\title{
A Study on Experiential Translation Teaching under Multimedia Network Environment*
}

\author{
Xiaowei Guan \\ School of Foreign Languages, Dalian University of Technology, Dalian, China \\ Email: angel_gxw@yahoo.com.cn \\ Dongmei Wang \\ School of Foreign Languages, Dalian University of Technology, Dalian, China \\ Rui Zhang \\ School of Foreign Languages, Dalian University of Technology, Dalian, China
}

\begin{abstract}
Experiential foreign languages teaching, which evolves out of the urgent need to reform the traditional language teaching models, is a new mode in foreign language teaching and learning in China. This paper introduces the theory of experiential foreign languages teaching, analyze its necessity, and proposes the its principles and approaches under multimedia network environment. Learners become self-motivated and obtain language communicative competence as a result of experiential "engagement, enjoyment and enhancement" in both a learner-oriented humanistic environment and a language learning ecological environment. Experiential translation teaching focuses on situational language teaching, interactive language leaning and application, teaching, engagement in teaching and independent learning, aiming at improving students' abilities of cognition, language and communication.
\end{abstract}

Index Terms - experiential translation teaching, experiential foreign languages teaching, multimedia network

In 2004, the Ministry of Education of China promulgated the "College English Curriculum Requirements (For Trial Implementation)" (2004) which marks the beginning of a new round of college English teaching reform. One of the most important parts of this reform is to vigorously promote the application of information technology in college English reform, seeking to use the new teaching model nationwide. "College English Curriculum Requirements" (2007) specified that the goal of college English teaching is to develop students' English language proficiency, so that they can communicate effectively in English in their future study, work and social interaction. English Teachers should apply a large number of advanced information technology into college English curriculum design, and develop and construct a variety of computer and network-based courses. Colleges and universities should improve the traditional teachercentered teaching pattern, and put forward new tasks for teaching content and methods, which will make English teaching develop towards personalized, self-learning direction.

Experiential teaching method is a new teaching model based on this philosophy for the purpose of promoting students' initiative development.

\section{INTRODUCTION TO EXPERIENTIAL TEACHING AND LEARNING THEORY}

"Experiencing" is the psychological and emotional phenomenon in the process of human's acquisition of knowledge and skills, and understanding of the objective world, and is also one of the basic problems of philosophy, aesthetics, education, linguistics, and many other disciplines. The study on experience can also explain and disclose the objective laws of human's understanding of the world.

In the early 1900s, J. Dewey (1938/1997), American educator, founded an educational movement based, at least in part, on the concept of "experience plus reflection equals learning". It is here that the origins of experiential learning can be seen, with Dewey's recognition of the importance of experience and reflection in learning.

Experiential teaching is extensively based on psychology, linguistics, philosophy and pedagogy. According to Rogers (1969), learning can be divided into cognitive learning and experiential learning. The former is built on the behaviorist theory of "Stimulus-Reaction", by which learning is restricted by external force while the latter focuses on students' experience growth and combines learning with students' interest and will.

In 1984, David Kolb (1984) provided one of the most useful descriptive models of the adult learning process available: beginning from concrete experience, to observation and reflection, then to the formation of abstract concepts and generalizations, to testing concepts in new situations, the learning cycle has become the most influential of its kind and many others have accepted this model as the basic model for experiential learning.

* This work was supported in part by a grant from Teaching Reform Fund of Dalian University of Technology (No. MS201280). 
H. H. Stern (1992) stated experiential teaching was theoretically and enormously strengthened through the development of Krashen's second language acquisition theory, and that since the mid-1970s immersion has been increasingly recognized as a prime example of experiential language teaching.

David Nunan (2001) pointed out, there appears to be a philosophical shift from transmission model of education to an experiential model, which has taken root, and is having a profound effect on all aspects of the curriculum. According to him, "Experiential learning is the process knowledge is created through the transformation of experience. It lays in whereby exploring the processes associated with making sense of concrete experiences and the different style of learning that maybe involved."

\section{EXPERIENTIAL ENGLISH TEACHING AND LEARNING THEORY}

Experiential English teaching derives from the experiential theory, reflecting the teaching philosophy of Constructivism. Experiential foreign language teaching theory believes that successful foreign language teaching should be that the learner is able to "wholeheartedly" plunge into the language learning activities to produce enjoyable feelings and positive attitudes in the process of activities, making learners feel the joy and achievement of learning to reach into the enhancement state with "cognitive objects" and enhance the cognitive level of the "object". The condition to realize this state is that teaching activities must create a language learning ecological and humanistic environments to conform to the positive experience, that is, a "harmonious" learning environment and condition will be provide by the teaching hardware, technical means, teachers' teaching activities and organization styles to meet the learners' positive mentality.

\section{A. Theory of Constructivism}

The theoretical basis of Experiential English teaching theory is the theory of Constructivism (He, 1997; Kong, 2003). The theory of Constructivism holds that learning is not a simple knowledge transfer from teachers to students, but the learners' individual self-knowledge construction process. Constructivists regard the process of learning as a positive and active process, emphasize taking students as centre. It highlights students' subjectivity and autonomy in meaning construction, in which students are transformed from passive recipients by external stimulation and instill object of knowledge into the main body of information discovery and processing by active participation and the active constructor of meaning. Teachers' role is transformed from imparting and instilling knowledge into organizing, instructing and helping students' study (Feng \& Cai, 2009). In the view of constructivist, learning is a constructive process in which the learner is building an internal illustration of knowledge, a personal interpretation of experience. This representation is continually open to modification, its structure and linkages forming the ground to which other knowledge structures are attached. The process of the construction is two ways. One is that learners construct the meaning of present things to trace the given information; the other is that the original knowledge is not simply taken out unchangeable, but constructed according to the variation of concrete situation. Learning is an active process in which meaning is accomplished on the basis of experience.

\section{B. Experiential Foreign Language Teaching}

Experiential foreign language teaching model regards the learners' gaining positive psychological experience as the driving force and orientation feature; scenarios, interaction, task or project, cooperative learning as the main methods. This new foreign language teaching model makes more use of the modern information technology to integrate foreign language teaching resources, builds the ecological environment of second language acquisition, creates the humanistic environment of foreign language learning, in which learners acquire language communicative competence through the mechanisms of experiential learning, such as engagement, enjoyment, enhancement and environment. "Engagement" means the students are no longer the objects of teaching, who simply "obtain" knowledge of foreign languages, but are the main body of teaching, who actively participate in the "acquisition" of language communication competence. "Enjoyment" refers to that the process of foreign language acquisition must be realized in state that the learners could feel enjoyable. "Enhancement" means when learners soul into learning, integrating the mood, thinking, ideas with the language content to form the state of spiritual enhancement. Only in this state, are the ideal conditions for the success of second language acquisition. "Environment" is the depending condition of the experiential mechanism of foreign language teaching. Foreign language teaching and learning environment refers to the language learning ecological environment and humanistic environment. The language learning ecological environment is consisted of the hardware environment of foreign language teaching resources, including different forms of materials, corpus resources, teaching scenes, teaching equipments, etc. The humanistic environment is consisted of by foreign language teaching modes, teaching methods, interpersonal association features in teaching, which is mainly reflected in the adoption of foreign language teaching methods, such as "cooperative learning", "teamwork" and "mutual learning".

Making full use of modern information technology, integrating abundant foreign language teaching resources, build the simulated ecological language environment to support the elements of "engagement" and "enjoyment" and" Enhancement" and the humanistic environment beneficial to interactive learning, and innovate teaching method, we can achieve the teaching objectives set by the experiential foreign language teaching mode (Liu, 2011).

The most prominent features of experiential foreign language teaching are that it focuses on students' feelings in foreign language learning, and strengthens the motivation of language learning, creates a language learning ecological 
language and humanistic environment conducive to independent learning. Therefore, it is a new foreign language teaching mode integrating era, humanities and scientificity, in which the connotation of experience is focused on the feelings of the learners in the learning process. How to motivate, maintain, and enhance students' motivation to learn is the purpose and significance of experiential foreign language teaching.

The core of experiential of English teaching is to learn the language skills, which provides students with the opportunities and conditions of knowledge conversion and comprehensive application of language skills. Experiential English teaching aims at make communication in language teaching authentic and the classroom socialized. This teaching mode makes use of the "task" in language learning to enable students to engage in communicative activities to achieve a specific goal. This task-based teaching mode lets students "learn in doing" and" practice focusing on application" (Kohonen, 1992), therefore it is conducive to the development of language skills.

From the learners' point of view, the experiential learning process is implicit learning. Ellis equates implicit learning to unconscious learning, that is the learners do not realize when, where and what they are learning, and the knowledge is accumulated gradually. How to use language used relies on the learners themselves to experience, induce and percept (Ellis, 1994).

\section{EXPERIENTIAL TRANSLATION TEACHING UNDER Multimedia NeTwOrK ENVIRONMENT}

\section{A. Necessity of Experiential Translation Teaching}

After the introduction of experiential teaching theory, it has been applied to many fields such as psychology, education, and so on. In 1960s, the United States began implement experiential teaching on a large scale; the overall quality of students has been greatly improved. In 1980s experiential teaching theory was introduces to Japan to start education reform. In China this theory began to receive attention in 1990s, which has been studied by many scholars from different angles in recent years. Most of the scholars mainly study the its theories and how to apply it to college English teaching.

Colina (2003) thinks that translation teaching should be student-centered, that is we must attach importance not only to students' reaching the standard at every stage, but also to the laws and characteristics of students' cognitive and thinking development while organizing and compiling the teaching materials. Therefore, experiential teaching should be implemented in foreign language teaching, and translation teaching is an important part of foreign language teaching, so the implementation of experiential teaching (experiential translation teaching) has become an inevitable trend in the teaching of translation.

\section{B. Experiential Translation Teaching Principles under Multimedia Network Environment}

\section{a. Principle of Environment}

To create ecological and humanistic environment is the important objective, principle and basis of experiential foreign language teaching, and is also the prerequisite of other experiential foreign language teaching principles. Experiential foreign language teaching is to produce a positive learning environment in favor of creating the inner experience of learners in a full range. Therefore it is necessary to adapt to the learning needs and subjective feelings of learners, and provide an ecological language learning environment to create a harmonious humanistic learning environment for them.

The authenticity of the language learning environment means that the language, characters and atmosphere in teaching activities must highly fit with the communication scene. This principle requires teachers to use a variety of technical and non-technical means, such as audio and video digital technology, network technology, corpus or props, wall charts to enrich context elements, so as to make learners feel immersive.

Real-time refers to the interactive relationship between the learner and learning objects. Therefore, teachers should take into consideration how to create the conditions for learning feedback while designing the course, and make use of modern educational technology, such as networks, digital technology for learners to create learning situation interaction.

\section{b. Principle of Engagement}

Experiential foreign language teaching aims to provide students with more accessible opportunities of participation in learning. Active and effective engagement in learning is a necessary condition for "enjoyment" experience. The teaching tasks designed by the teaching organizers are to enable students to actually feel their own dominant positions, put students into language learning activities to the maximum, and create effective experiential effect. This kind of activity is designed to have a clear communication or learning objective, in which students can produce clear results of the activities. In the appropriate language learning ecological and humanistic environment, learners are able to maximize the engagement in the task of language learning, and complete the tasks in equal, friendly, consulting and independent atmosphere.

\section{c. Principle of Enjoyment}

The positive experience of experiential foreign language teaching and learning activities are always closely related to the "enjoyment" of the students. Without bringing students enjoyable learning, they would be difficult to stimulate, maintain and enhance learners' interests. Learners will not only enjoy the ownership feelings in the learning process, but also the "enjoyment" brought about by their own learning values. The teaching designers must be good at making 
learning "challenge" converted to students' interest rather than the barriers to retreat. Only facing the challenge in the "enjoyment", could the necessary conditions be created to integrating the "enhancement" of subject and object.

\section{d. Principle of Enhancement}

On the basis of $t$ ideal language learning environment, experiential foreign language teaching aims to make the learners get an enjoyable experience, continue to experience until succeed, and have a positive evaluation of their own learning process and results, thus they can achieve the enhancement with learning object and eventually achieve the goal of teaching and learning. The responsibility of teaching organizers is to provide "frame" for the learner, help learners to reach the height that they can not get by their own power to complete the task they can not complete by their own strength. Teachers help learners to experience "success", to enhance their learning autonomy and self-confidence, so as to build a continuous learning dynamical system.

\section{Approach to Experiential Translation Teaching under Multimedia Network Environment}

According to Qian Chunhua (2011), the core entries of experiential teaching include (1) situational experiential: trying to imitate the situation in the teaching content; (2) fact restoring: restoring abstract knowledge into facts; (3) autonomous learning: achieving learning objectives through students' independent analysis, exploration, practice, questioning, and creation; (4) active engagement: students actively learn and engage; 5) interactive leaning and application: applying the language while learning, and vice versa; (6) the application of entertaining into teaching: regarding learning as an interesting recreational activity.

Translation teaching is an activity with definite purpose. First of all, teachers should enhance students' cognitive thinking skills, such as intuition, concept and logical reasoning and information processing abilities; then the language skills including language knowledge, expressing skills and language perception; finally the interpersonal skills including language for language receptive ability, creativity and associative thinking ability. Therefore, in order to enhance students' cognitive ability, language ability and communicative skills, experiential translation teaching focuses on situational teaching, interactive learning and applying, teaching participation and independent learning.

\section{a. Situational Language Teaching}

Situational approach in translation teaching means that in the translation classroom, teachers purposefully introduce or create vivid source language context with emotional color and image, lead the students into the context of translation materials, so that they can deeply understand writer's mental state which will stimulate their creativity and imagination to help them to effectively complete translation tasks, and to further enhance their translation capabilities. The specific forms of situational translation teaching include vivid language description, curricular games, role-playing, poetry readings, music, films and so on. For example, teachers can organize students to practice translating the classic lines in the English films in the classroom, in order to exercise students to practice translation in the specific movie plot, and let them gain the Western historical and cultural background knowledge.

The core of situational approach is to stimulate students' emotions, to enable students to think, discuss, and cooperate facing the situation restored, truly feel the feelings and ideological formation and exchange under teachers' guidance. In this case, students will actively participate in the tasks, establish the target to match their own needs, unwittingly become involved in the activity, and psychologically withdraw antagonism with the teachers to reach the state of unification of consciousness and activities.

\section{b. Interactive Language Leaning and Application}

Students obtain knowledge in the context, and apply the knowledge learned into the context. Interactive Language Leaning and Application is a concept which is shifted from one-way imparting to interactive two-way experience, and is the core idea of constructivism. Traditional translation teaching is still spoon-feeding teaching. Teachers impart knowledge in accordance with the established teaching mode, which lacks the place, time and opportunity to apply knowledge to solve practical problems, although a lot of knowledge is taught. In this way, students do not know what language should be the most appropriate, most able to express their ideas in a real environment. Therefore, Teachers should let learners come to realize that language learning is a step-by-step process through practical application, and should increase the opportunity to practice in teaching and learning, guide students to construct knowledge in practice. Students often lack systematic and logical cognition of the knowledge, so teachers should play an important role in the classroom training to guide students to process the translation information and organize language effectively to improve completely in language cognition and communication.

\section{c. Engagement in Teaching}

Teachers should let students actively engage in the teaching and learning process, whose role will be transformed from passive learning to active learning. In translation teaching, teachers will design teaching content according to students' actual needs and aspirations, so that they will truly feel the real fun of being the master of learning, and the happiness of exploring the common knowledge with teachers and other students. This teaching method encourages students to actively participate in the teaching process, which can enhance the exchange of information between teachers and learners to enable them to deeply understand and master the knowledge, and to apply the knowledge into practice.

Students are involved in designing teaching and learning targets and progress, which plays incentive role for the completion of the target. They are encouraged to actively develop various thinking strategies in the translation process, and to learn in solving the problem continuously. Teachers should guide students to increase their emotional input, 
stimulate their intrinsic motivation, so that they can gain emotional experience and deep understanding of knowledge, and master translation skills gradually unobtrusively and imperceptibly. Teachers should also help students to selfmonitor in the practice of translation; raise questions and construct knowledge in alternately spiral rising.

\section{d. Independent Learning}

Students should achieve their learning objectives by independent analysis, exploring, practice, questioning, and creating. In teaching activities, teachers' and students' roles are reversed. Before experiential, students should carefully prepare for the topics and presentation, organize the materials, seriously carry out the self-assessment and peer assessment after the presentation, and teachers should summarize.

This experiential method enables students in high spirits, make classroom atmosphere active, to enable students to experience the joy in learning English, and truly become the main part of learning English. This teaching model is bound to improve the efficiency of classroom teaching and independent learning ability by combing traditional classroom teaching with the network self-learning. Teachers should not only teach students the language knowledge and skills, but also pay more attention to cultivate their abilities of using the language and self-learning to effectively promote students' independent learning capabilities. The learning environment for students should be optimized to form three-dimensional network programs, and construct English-Chinese Translation Corpus and translation network teaching platform.

\section{The Role of Learners and Teachers in Experiential Translation Teaching under Multimedia Network Environment}

Experiential teaching requires teachers to play multiple roles. Firstly, teachers, as lectures, should impart language knowledge (resources). Secondly, teachers, as organizers, should create English communication environment for students, and organize students to fulfill the tasks. Thirdly, teaches, as facilitators, should induce students to complete learning tasks and goals through active learning. Finally, teachers, as mentors, should give their assessment of each student for each unit of learning, and point out their deficiencies, so that they can improve in learning.

The status of students changes from passive recipients into active constructors of knowledge meaning. Students can take the initiative to learn, and the contents of textbooks once imparted by teachers change into students' independent learning, in which students make full use of learning resources provided by the network to compensate for the limitations of knowledge and teaching materials. They become responsible, reflective and creative learners. The knowledge provided by the textbook is no longer the content taught by teachers, but students' object of the active meaning construction. Media is no longer a means, and method to help teachers to impart knowledge, but is used to create scenarios for collaborative learning and session exchanges, namely, as cognitive tools for students' active learning and collaborative exploration.

\section{CONCLUSION}

The traditional teacher-centered teaching model can not satisfy the college English teaching objectives. With development of modern information technology, it requires universities to make use of multimedia and network technology in the new English teaching mode.

The fundamental difference between experiential translation teaching and traditional translation teaching lies in that the former emphasizes the learner-centered independent learning, while the latter emphasizes the teacher-centered knowledge transfer. Experiential learning emphasizes on learning from direct experience, and emphasizes that the learners act on their autonomous learning. The essential characteristics of experiential translation teaching are in line with students' cognitive learning law. Experiential translation teaching under multimedia network environment promote a combination of classroom teaching and independent learning, and adopt modern educational technology, i.e. combine networks, computers with classroom teaching, emphasizing the use of a variety of information resources to support learning, simulating and designing a virtual English communication environment to develop students' independent learning and communicative learning.

\section{ACKNOWLEDGMENT}

This work was supported in part by a grant from Teaching Reform Fund of Dalian University of Technology (No. MS201280).

\section{REFERENCES}

[1] Colina, S. (2003). Translation teaching: From research to the classroom: A handbook for teachers. Boston BurrRidge: McGraw2Hill.

[2] Dewey, J. (1938/1997). Experience and education. New York: Siman and Schuster.

[3] Ellis, R. (1994). The study of second language acquisition. Oxford: Oxford University Press.

[4] Feng, Y. F. and Cai, L. (2009). A research-oriented approach to college English integrated reading course under multimedia environment. Foreign Languages and Their Teaching, 11, 28-31.

[5] He, K.K. (1997). Teaching patterns, methods and design of Constructivism. Journal of Beijing Normal University (Social Sciences), 5, 74-81. 
[6] Higher Education Department of Education Ministry. (2004). College English curriculum requirements (For Trial Implementation). Shanghai: Shanghai Foreign Language Education Press.

[7] Higher Education Department of Education Ministry. (2007). College English curriculum requirements. Beijing: Foreign Language Teaching and Research Press.

[8] Kohonen, V. (1992). Experiential language leaning: Second language learning as cooperative learner education. In D. Nunan (ed.), Collaborative Language Learning and Teaching. Cambridge University Press.

[9] Kolb, D. (1984). Experiential learning: Experience as the source of learning and development. Englewood Cliffs, NJ: Prentice Hall.

[10] Kong, Q.Y., Hu, Z.L., Gui, S.C., Jia, G.D. (2003). On “College Experiential English”. China University Education, 8, 39-41.

[11] Liu, Y. (2011). Practice and theory exploration of Experiencing English Teaching. Foreign Languages in China, 8(5), 57-64.

[12] Nunan, D. (2001). Tradition and change in the ELT curriculum. Foreign Language Teaching and Research, 33/4, $252-257$.

[13] Qian, C.H, and Huang, M. (2011). Experiential translation teaching and the improvement of students' translation abilities. Literature Education, 10, 128-129.

[14] Rogers, C.R. (1969). Freedom to learn: A view of what education might become. Columbus, Ohio: Charles E. Merrill Publishing Company.

[15] Stern, H. H. (1992). Issues and Options in Language Teaching. Oxford: Oxford University Press.

Xiaowei Guan was born in Shenyang, China in 1979. She received her PH.D. degree in machine translation from Dalian University of Technology, China, in 2009.

She is currently a lecturer in the School of Foreign Languages, Dalian University of Technology, Dalian, China. Her research interests include machine translation and natural language processing, E-C and C-E translation and contrast.

Dongmei Wang was born in Changchun, China in 1977. She received her Master's degree in foreign languages and literatures from Jilin University, China, in 2002.

She is currently a lecturer in the School of Foreign Languages, Dalian University of Technology, Dalian, China. Her research interests include cognitive linguistics and foreign language teaching.

Rui Zhang was born in Liaoning, China in 1972. She received her Master's degree in foreign linguistics and applied linguistics from Dalian University of Technology, China, in 2007.

She is currently an associate professor in the School of Foreign Languages, Dalian University of Technology, Dalian, China. Her research interests include interpretation theory and foreign language teaching. 